\title{
Performance of an Iterative Two-stage Bayesian Technique for Population Pharmacokinetic Analysis of Rich Data Sets
}

\author{
Johannes H. Proost ${ }^{1,2,3}$ and Douglas J. Eleveld ${ }^{1}$
}

In the December 2006 issue of Pharmaceutical Research (Vol. 23, No. 12, pages 2748-2759), there occurred two errors in the above manuscript. The correct information is as follows:

1. Equation (6) that appeared on page 2750 is incorrect. The correct equation for the calculation of the elements of matrix $\left[\alpha_{k}\right]$ is shown below:

$$
\alpha_{k, p, q}=\sum_{i=1}^{n_{k}}\left\{\frac{1}{\sigma_{\mathrm{res}, k, i}^{2}} \frac{\partial Y_{\mathrm{calc}, k, i}}{\partial P_{p}} \frac{\partial Y_{\mathrm{calc}, k, i}}{\partial P_{q}}\right\}+\left[\mathrm{COV}_{\mathrm{pop}}\right]_{p, q}^{-1}
$$

2. The author of reference 6 is S. Guzy.

\footnotetext{
${ }^{1}$ Research Group for Experimental Anesthesiology and Clinical Pharmacology, Department of Anesthesiology, University Medical Center Groningen, University of Groningen, PO Box 30001, 9700 RB Groningen, The Netherlands.

${ }^{2}$ Department of Pharmacokinetics and Drug Delivery, University Centre for Pharmacy, University of Groningen, Groningen, The Netherlands.

${ }^{3}$ To whom correspondence should be addressed. (e-mail: j.h.proost@rug.nl)
}

The online version of the original article can be found at: http://dx.doi.org/10.1007/s11095-006-9116-0. 